\title{
THE COLLECTION AND COMPOSITION OF EPIDIDYMAL PLASMA FROM THE CAUDA EPIDIDYMIDIS OF THE RABBIT
}

\author{
R. JONES* AND T. D. GLOVER \\ Unit of Reproductive Biology, University of Liverpool, \\ P.O. Box 147, Liverpool L69 3BX
}

(Received 24th fuly 1972)

\begin{abstract}
Summary. A technique is described for collection of the epididymal contents from the cauda epididymidis of anaesthetized rabbits. The technique avoids undue contamination of the epididymal contents with blood or tissue fluid and overcomes the difficulty of post-mortem change.

The effects of high-speed centrifugation and cold shock on the composition of epididymal plasma have also been investigated, and it has been shown that lactic dehydrogenase and glutamic-oxaloacetic transaminase are largely intracellular constituents, whilst sodium, potassium, acid phosphatase, alkaline phosphatase and $\beta$ - $\mathcal{N}$-acetylglucosaminidase are extracellular. Finally, some results are presented on the overall composition of epididymal plasma in the rabbit.
\end{abstract}

\section{INTRODUCTION}

The composition of the fluid or 'plasma' that suspends spermatozoa as they are transported through the epididymis has been investigated on numerous occasions (Scott, Wales, Wallace \& White, 1963; Crabo \& Gustafsson, 1964; Mann, 1964; Crabo, 1965; Wales, Wallace \& White, 1966), but progress in this field has been hampered largely by the difficulties of collecting sufficient quantities of the plasma for analysis. Mostly, slaughterhouse material has been used and the luminal contents have been collected by direct puncture of the epididymal tubules (see Crabo, 1965). This method is open to considerable error as a result of contamination with blood or tissue fluid, and the collection procedure itself may take several hours. The precautions taken by various workers to overcome these problems have varied considerably and this probably accounts for many discrepancies that are reported in the literature.

In addition, the separation of spermatozoa from the plasma is a problem which has not been investigated adequately. It has often been stressed that procedures that injure spermatozoa, such as high-speed centrifugation or cold shock, cause leakage of their intracellular proteins and coenzymes into the supernatant plasma (Mann \& Lutwak-Mann, 1955; Mann, 1964; Graham \& Pace, 1967; Pace \& Graham, 1970). Since centrifugation is commonly used

* Present address: A.R.C. Unit of Reproductive Physiology and Biochemistry, 307 Huntingdon Road, Cambridge, U.K. 
for separating epididymal plasma from spermatozoa, some of the constituents of the plasma might have their origin in the spermatozoa and might not be truly extracellular.

The aims of the present work, therefore, were to develop techniques for the collection of epididymal plasma from the cauda epididymidis of anaesthetized rabbits, and to investigate the chemical composition of the plasma so obtained.

\section{MATERIALS AND METHODS}

The terminology of Crabo \& Gustafsson (1964) is used throughout, so that the term 'epididymal content' refers to both the fluid and spermatozoa in any one region of the epididymis, and 'epididymal plasma' refers only to the supernatant after centrifugation of the epididymal content.

\section{Collection of epididymal contents from the cauda epididymidis}

Adult male rabbits were anaesthetized with an intravenous injection of sodium pentabarbitone (Nembutal, Abbott Laboratories), and the testis, epididymis and ductus deferens were exposed through a scrotal incision and placed on a piece of clean gauze. Care was taken not to interfere with the blood supply. The ductus deferens was cannulated close to the cauda epididymidis with a polythene cannula (o.d. $1 \mathrm{~mm}$, i.d. $0.5 \mathrm{~mm}$ ) partially filled with mineral oil (Nujol, Boots Ltd) and tipped with a 25-gauge needle (Text-fig. 1a). This enabled the cannula to be inserted directly into the lumen of the duct with a minimum of trauma and the mineral oil prevented any blood or tissue fluid from being drawn up the cannula by capillary action. A small metal electrode delivering 0.5 to $1.0 \mathrm{~V}$ was used to stimulate contraction of the smooth muscle in the wall of the epididymal tubules and this pumped the epididymal contents out of the more proximal regions of the cauda epididymidis into the ductus deferens where it was sucked up into the cannula (Text-fig. $1 \mathrm{~b}$ ). In this way, volumes of between 25 and $75 \mu$ 1 per epididymis could be collected without difficulty.

The epididymal content was transferred under mineral oil to clean glass capillary tubes (o.d. $1.4 \mathrm{~mm}$, i.d. $1.0 \mathrm{~mm}$, Hawksley Ltd) which were heatsealed at one end in a hot flame to localize the area of heating (Text-fig. 1 c to f). The epididymal content, trapped between two columns of mineral oil (Text-fig. $1 \mathrm{~g}$ to $\mathrm{h}$ ) was centrifuged in a microhaematocrit centrifuge (Hawksley Ltd) fitted with a Variac transformer. After centrifugation, the 'spermatocrit' or packed cell volume, expressed as a percentage, and the volume of plasma collected were recorded. The plasma was then separated and stored in polythene 'BEEM' capsules (TAAB Laboratories) under mineral oil at $-20^{\circ} \mathrm{C}$ (Textfig. 1 i).

The following experiments were carried out in order to determine the conditions of centrifugation under which there was maximal separation of spermatozoa together with a minimal effect on the composition of the supernatant plasma.

Experiment 1. The effect of centrifugation on the composition of the epididymal plasma

The contents of each cauda epididymidis were collected from three rabbits 


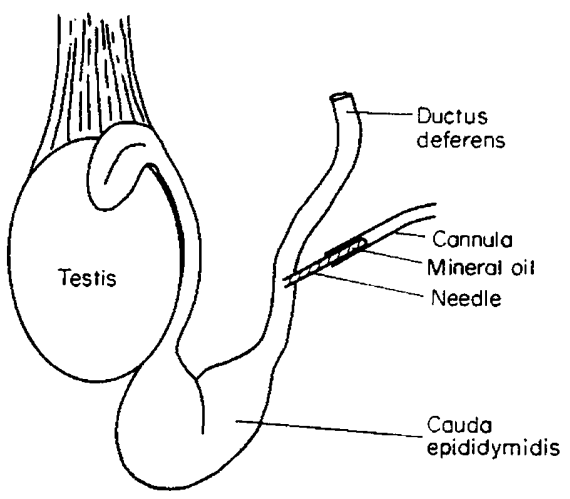

(o)

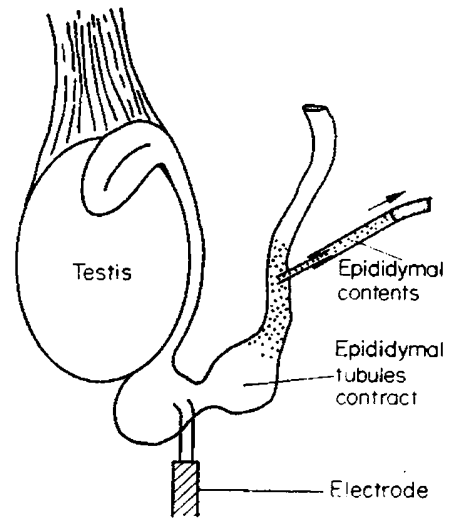

(b)

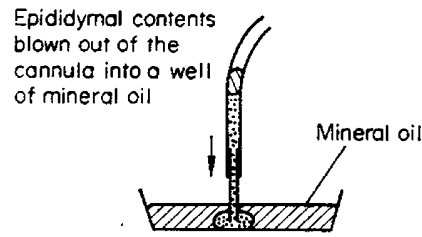

(c)

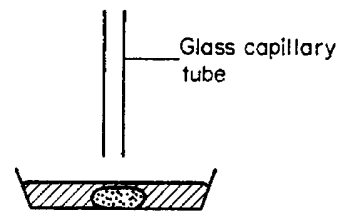

(d)

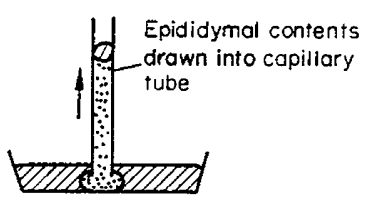

(e)

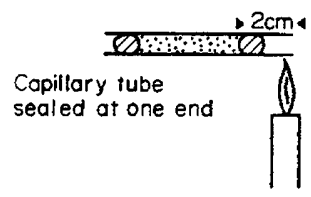

(f)

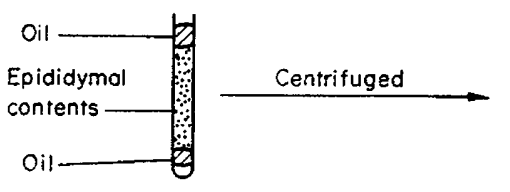

(g)

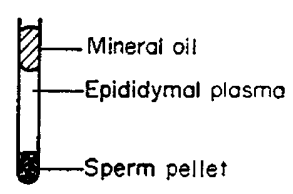

(h)

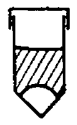

Epididymal plasma separated and stored under mineral oil at $-20^{\circ} \mathrm{C}$ in a 'BEEM' capsule

(i)

TexT-FIG. 1. Flow diagram of the technique used for collection of the epididymal plasma from the cauda epididymidis of rabbits (see text).

and samples from each animal were subjected to three different treatments. Sample 1 was centrifuged at $4000 \mathrm{~g}$ for $5 \mathrm{~min}$, Sample 2 at $12,000 \mathrm{~g}$ for $5 \mathrm{~min}$ and Sample 3 was subjected to cold shock by plunging onto ice at $-20^{\circ} \mathrm{C}$ for $10 \mathrm{~min}$ before centrifuging at $12,000 \mathrm{~g}$ for $5 \mathrm{~min}$. The spermatocrit was measured and the plasma analysed for sodium, potassium, alkaline phosphatase, acid phosphatase, $\beta$ - $\mathcal{N}$-acetylglucosaminidase, lactic dehydrogenase (LDH) 
and glutamic-oxaloacetic transaminase (GOT). Spermatozoa from the sperm pellet were stained with aqueous nigrosin-eosin (see Campbell, Dott \& Glover, 1956) and the percentage of stained ('dead') spermatozoa was estimated from counts of 300 spermatozoa in duplicate smears.

Experiment 2. The effect of time of centrifugation at $12,000 \mathrm{~g}$ on the composition of epididymal plasma

The contents of each cauda epididymidis were collected from three rabbits as described in Exp. 1 and aliquots from each sample were centrifuged at $12,000 \mathrm{~g}$ for 5,10 and $20 \mathrm{~min}$. The spermatocrit, the percentage of stained spermatozoa in the sperm pellet, and the levels of $\mathrm{LDH}$ in the plasma were measured as described in Exp. 1.

\section{Analytical methods}

Eppendorf microtest-tubes and Eppendorf micropipettes (V. A. Howe Ltd, London) were used in all analytical procedures involving microanalysis. Volumes below $5 \mu \mathrm{l}$ were pipetted from Lang-Levy construction pipettes pulled from Pyrex glass tubing (o.d. $5 \mathrm{~mm}$, i.d. $3 \mathrm{~mm}$ ) according to the instructions of Bessy, Lowry \& Brock (1946) and calibrated colorimetrically using $p$-nitrophenol (Lowry, Roberts, Leiner, Wu \& Farr, 1954). These construction pipettes were found to be the most suitable means of measuring small volumes of epididymal plasma accurately.

An EEL atomic absorption spectrophotometer (model 240) incorporating a flame photometer was used for cation analysis. All spectrophotometric work was carried out on a Cecil Instruments (Cambridge) GE 303 spectrophotometer fitted with 1-cm path-length microcells. Osmotic pressure was measured on a Ramsay micro-freezing-point apparatus as modified by Tuft \& Böving (1970).

All the methods used were no more than microadaptions of standard analytical procedures and each assay was carried out in duplicate or triplicate.

Sodium and potassium were estimated by flame photometry and magnesium by atomic absorption spectroscopy (EEL Technical Catalogue). Chloride was measured titrometrically by the method of Schales \& Schales (1941), and total protein by the Biuret reaction of Weichselbaum (1946) using $5 \%$ bovine serum albumin (Sigma, London) as standard. Glycerylphosphorylcholine (GPC) was estimated by the periodate oxidation method of White (1959), who demonstrated its suitability for the determination of GPC in semen. The presence of fructose was tested for by the method of Mann (1946) and inorganic phosphate was determined by the molybdate reaction (Fiske \& Subbarow, 1925) after deproteinization with ice-cold $10 \%(\mathrm{w} / \mathrm{v})$ trichloroacetic acid (TCA). Acid phosphatase and alkaline phosphatase were measured colorimetrically, using $p$-nitrophenylphosphate as substrate (Boehringer test kits) and LDH and GOT were determined spectrophotometrically at $340 \mathrm{~mm}$ (Boehringer test kits). $\alpha$-Mannosidose and $\beta$ - $\mathcal{N}$-acetylglucosaminidase were estimated by the method of Conchie, Findlay \& Levvy (1959), using the corresponding $p$-nitrophenylglycoside as substrate (Sigma). Osmotic pressure was determined as freezingpoint depression (Tuft \& Böving, 1970) and $\mathrm{pH}$ was estimated by pipetting $1-\mu 1$ aliquots of plasma directly onto Universal $\mathrm{pH}$ paper (Microessentials 
Laboratories, New York). The colour was compared to that developed by buffers in the appropriate $\mathrm{pH}$ range and treated in a similar fashion.

\section{RESULTS}

The results of Exp. 1 (Table 1) show that increasing the force of centrifugation from $4000 \mathrm{~g}$ to $12,000 \mathrm{~g}$ gives rise to a decrease in the spermatocrit from $40.9 \%$ to less than $20.0 \%$ (difference highly significant, $P<0.001$ ). At the same time there was an increase in the incidence of stained spermatozoa in the sperm pellet; the difference between values after centrifugation at $4000 \mathrm{~g}$ and $12,000 \mathrm{~g}$ was not significant $(P<0 \cdot 05)$, but both values were significantly different from spermatozoa which had been subjected to cold shock and centrifuged at $12,000 \mathrm{~g}$ $(P<0.001)$.

Table 1. The effect of the force of centrifugation and cold shock on the incidence of stained spermatozoa in the sperm pellet and on the composition of plasma from the cauda epididymidis of the rabbit

\begin{tabular}{l|c|c|c}
\hline & $4000 \mathbf{g}$ & $12,000 \mathbf{g}$ & Cold shock+12,000 $\mathbf{g}$ \\
\hline Spermatocrit (\%) & $40 \cdot 99 \pm 10 \cdot 14$ & $19 \cdot 22 \pm 3 \cdot 7 * * *$ & $17 \cdot 36 \pm 3 \cdot 01 * * * *$ \\
Stained spermatozoa (\%) & $23 \cdot 0 \pm 2 \cdot 95$ & $35 \cdot 62 \pm 3 \cdot 71$ & $98 \cdot 77 \pm 0 \cdot 10^{* * * *}$ \\
Sodium (mequiv./litre) & $15 \cdot 0 \pm 1 \cdot 09$ & $14 \cdot 91 \pm 0 \cdot 96$ & $14 \cdot 74 \pm 1 \cdot 12$ \\
Potassium (mequiv./litre) & $22 \cdot 17 \pm 1 \cdot 54$ & $22 \cdot 26 \pm 0 \cdot 49$ & $22 \cdot 55 \pm 1 \cdot 15$ \\
Acid phosphatase (i.u.) & $273 \cdot 0 \pm 24 \cdot 58$ & $235 \cdot 00 \pm 25 \cdot 1$ & $266 \cdot 00 \pm 24 \cdot 68$ \\
Alkaline phosphatase (i.u.) & $13,730 \pm 1757 \cdot 6$ & $13,160 \pm 1707$ & $12,160 \pm 1491 \cdot 1$ \\
$\beta-\mathcal{N}$-acetylglucosaminidase (i.u.) & $17,750 \pm 3339 \cdot 2$ & $16,670 \pm 2408$ & $13,200 \pm 1946 \cdot 4$ \\
GOT (i.u.) & $7 \cdot 2 \pm 1 \cdot 82$ & $15 \cdot 9 \pm 3 \cdot 12$ & $1900 \pm 207 * * *$ \\
LDH (i.u.) & $1143 \pm 125$ & $1676 \pm 322$ & $33,528 \pm 1333^{* * *}$ \\
\hline
\end{tabular}

Values given are the means for three animals with their standard errors. Centrifugation time $=5 \mathrm{~min}$. i.u. = International Units $\left(\mu \mathrm{mol}\right.$ substrate hydrolysed $/ \mathrm{min} /$ litre at $\left.37^{\circ} \mathrm{C}\right)$.

** Significantly different from $4000 \mathrm{~g}(P<0.01)$.

*** Significantly different from $4000 \mathrm{~g}(P<0.001)$.

There was a positive correlation between the incidence of stained spermatozoa and the levels of GOT $(r=0.98, P<0.01)$ and LDH $(r=0.99, P<0.01)$ in the supernatant plasma. The difference in GOT activity between $4000 \mathrm{~g}$ and $12,000 \mathrm{~g}$ was not significant $(P>0.05)$ but the difference for $\mathbf{L D H}$ activity was significant $(P<0 \cdot 01)$. Cold shock and centrifugation at $12,000 \mathrm{~g}$ resulted in very high levels of GOT and LDH appearing in the plasma and these were significantly different from all other treatment groups $(P<0.001)$. The levels of sodium, potassium, acid phosphatase, alkaline phosphatase, and $\beta$ - $\mathcal{N}$-acetylglucosaminidase in the plasma were not, however, significantly different between treatment groups $(P>0.05)$, nor were they correlated to the incidence of stained spermatozoa in the spermatocrit.

Increasing the time of centrifugation at $12,000 \mathrm{~g}$ from $5 \mathrm{~min}$ to 10 or $20 \mathrm{~min}$ (Table 2) did not cause a significant decrease in the spermatocrit $(P>0.05)$ although it caused a significant increase in the percentage of stained spermatozoa in the sperm pellet. The difference in the percentage of stained spermatozoa between $5 \mathrm{~min}$ and $10 \mathrm{~min}$ was just significant $(P<0.05)$ but between 
Table 2. The effect of time of centrifugation at $12,000 \mathrm{~g}$ on the composition of plasma from the cauda epididymidis of the rabbit

\begin{tabular}{|c|c|c|c|}
\hline & $5 \min$ & $10 \mathrm{~min}$ & $20 \mathrm{~min}$ \\
\hline $\begin{array}{l}\text { Spermatocrit }(\%) \\
\text { Percentage of stained spermatozoa }(\%) \\
\text { LDH (i.u) }\end{array}$ & $\begin{aligned} & 23 \cdot 45 \pm 0 \cdot 7 \\
& 16 \cdot 0 \pm 0 \cdot 57 \\
& 460 \cdot 56 \pm 42 \cdot 2\end{aligned}$ & $\begin{array}{r}20 \cdot 0 \pm 0.94 \\
25 \cdot 0 \pm 1 \cdot 73^{*} \\
501 \cdot 2 \pm 15 \cdot 62\end{array}$ & $\begin{array}{l}20 \cdot 23 \pm 0 \cdot 72 \\
37 \cdot 0 \pm 2 \cdot 08^{* *} \\
806 \cdot 0 \pm 21 \cdot 9^{* *}\end{array}$ \\
\hline
\end{tabular}

Values given are the means for three animals with their standard errors. i.u. = International Units ( $\mu \mathrm{mol}$ substrate hydrolysed $/ \mathrm{min} /$ litre at $37^{\circ} \mathrm{C}$ ).

* Significantly different from $5 \mathrm{~min}(P<0 \cdot 05)$.

** Significantly different from $5 \mathrm{~min}(P<0.01)$.

$5 \mathrm{~min}$ and $20 \mathrm{~min}$, it was highly significant $(P<0.001)$. The levels of LDH in the plasma were significantly different between $5 \mathrm{~min}$ and $20 \mathrm{~min}(P<0.01)$ but were not significantly different between $5 \mathrm{~min}$ and $10 \mathrm{~min}(P>0.05)$.

The composition of epididymal plasma from the cauda epididymidis of normal intact animals is shown in Table 3 . Here, the epididymal contents were centrifuged at $12,000 \mathrm{~g}$ for $5 \mathrm{~min}$.

Table 3. The composition of plasma from the cauda epididymidis of the rabbit*

\begin{tabular}{|c|c|c|}
\hline Characteristic or constituent & $M e a n \pm S . E$. & $\begin{array}{l}\text { No. of } \\
\text { animals }\end{array}$ \\
\hline $\begin{array}{l}\text { Spermatocrit (\%) } \\
\text { Sodium (mequiv./litre) } \\
\text { Potassium (mequiv/litre) } \\
\text { Magnesium (mequiv./litre) } \\
\text { Chloride (mequiv./litre) } \\
\text { Total protein (mg/100 ml) } \\
\text { Glycerylphosphorylcholine }(\mathrm{mg} / 100 \mathrm{ml}) \\
\text { Inorganic phosphorus (mg/100 ml) } \\
\text { Fructose (mg/100 ml) } \\
\text { Osmotic pressure }\left(\Delta \mathrm{T}_{\ell},{ }^{\circ} \mathrm{C}\right) \\
\text { pH } \\
\text { Acid phosphatase (i.u.) } \\
\text { Alkaline phosphatase (i.u.) } \\
\alpha-M a n n o s i d a s e ~(i . u .) \\
\beta \text { - } \mathcal{N} \text {-acetylglucosaminidase (i.u.) } \\
\text { Lactic dehydrogenase (i.u.) }\end{array}$ & $\begin{array}{c}20 \cdot 43 \pm 2 \cdot 02 \\
20 \cdot 73 \pm 2 \cdot 33 \\
24 \cdot 80 \pm 1 \cdot 21 \\
14 \cdot 02 \pm 2 \cdot 66 \\
9 \cdot 18 \pm 0 \cdot 99 \\
4033 \pm 227 \cdot 7 \\
766 \cdot 6 \pm 41 \cdot 59 \\
12 \cdot 42 \pm 1 \cdot 03 \\
\text { Undetectable } \\
0 \cdot 580 \pm 0 \cdot 035 \\
6 \cdot 72 \pm 0 \cdot 16 \\
106 \cdot 0 \pm 41 \cdot 13 \\
16,650 \cdot 0 \pm 1460 \cdot 0 \\
912 \cdot 0 \pm 183 \cdot 5 \\
21,890 \cdot 0 \pm 4741 \cdot 0 \\
648 \cdot 47 \pm 90 \cdot 98\end{array}$ & $\begin{array}{l}8 \\
5 \\
5 \\
5 \\
5 \\
5 \\
5 \\
5 \\
5 \\
5 \\
5 \\
5 \\
5 \\
3 \\
6 \\
4\end{array}$ \\
\hline
\end{tabular}

$\Delta T_{q}=$ depression of freezing point.

i.u. = International Units ( $\mu \mathrm{mol}$ substrate hydrolysed/min/litre at $37^{\circ} \mathrm{C}$ ).

* Epididymal contents centrifuged at $12,000 \mathrm{~g}$ for $5 \mathrm{~min}$.

\section{DISCUSSION}

The epididymal contents collected by the cannulation procedure described in this work are free of contamination with blood or tissue fluid and are of sufficient quantity to allow a more extensive chemical analysis to be made than has hitherto been possible. It is enough to stimulate the cauda epididymidis only once or twice with the electrode in order to initiate vigorous contraction of the epididymal tubules. Continuous stimulation is unnecessary. 
The present work confirms that the composition of epididymal plasma can be seriously affected by procedures that damage spermatozoa and cause leakage of their intracellular constituents. This problem is particularly relevant to epididymal contents where there is a high concentration of spermatozoa and where methods of separating spermatozoa other than by centrifugation are unsuitable because of the small volumes of fluid involved. The results do show, however, that whilst centrifugation at $12,000 \mathrm{~g}$ inevitably damages some spermatozoa, its effects can be reduced to a workable level by reducing the time of centrifugation to $5 \mathrm{~min}$. Centrifuging epididymal contents at $4000 \mathrm{~g}$ for prolonged periods of time (20 min) was not a satisfactory alternative, because it did not result in maximum packing of spermatozoa in the sperm pellet and spermatozoa were therefore frequently found in the supernatant. The possibility that centrifugation caused a reduction in the volume of spermatozoa cannot be discounted entirely, but it is unlikely to account for a decrease in the spermatocrit of over $50 \%$ between $4000 \mathrm{~g}$ and $12,000 \mathrm{~g}$.

Before any component of the epididymal plasma can be said to be truly extracellular, it is necessary to check for its release from spermatozoa either by prolonged centrifugation at high speed or after cold shock. On these grounds, it can be said that LDH and GOT originate in the spermatozoa, whilst sodium, potassium, acid phosphatase, alkaline phosphatase, and $\beta$ - $\mathcal{N}$-acetylglucosaminidase are truly extracellular. This finding is in agreement with the earlier observations of Graham \& Pace (1967) on ejaculated bull semen, although these workers also found some evidence for the release of acid phosphatase as did Nath \& Patt (1970) and Murdoch \& White (1968) using ram spermatozoa that had been subjected to cold shock. In the present work, however, an increase in the activity of acid phosphatase was not detected, irrespective of the amount of damage to the spermatozoa, so it would appear that the amount of acid phosphatase released from the spermatozoa was insufficient to affect the total activity in the plasma.

The $1: 1$ ratio of sodium to potassium reported here in plasma taken from the cauda epididymidis of rabbits is in agreement with the results of previous workers using rams (Scott, Wales, Wallace \& White, 1963; Jones, 1973), bulls (Crabo \& Gustafsson, 1964; Wales, Wallace \& White, 1966) and boars (Mann, 1964; Crabo, 1965). The rat and hamster appear to be exceptions since the ratios are 1:2.67 and $1: 1.58$, respectively (Levine \& Marsh, 1971; Jones, 1973). The relatively high concentration of magnesium found in the epididymal plasma suggests that the epididymis may be an important source of this cation in the ejaculate, since rabbit semen also has high levels of magnesium (Quinn, White \& Wirrick, 1965). The concentration of chloride ions by contrast, is similar to that reported by Crabo (1965) for bulls and boars and by Levine \& Marsh (1971) for the rat.

The hypertonicity of epididymal plasma $\left(0.58^{\circ} \mathrm{C}\right.$ as against $0.57^{\circ} \mathrm{C}$ for blood plasma) is in agreement with that reported by Salisbury \& Cragle (1956), Scott, Wales, Wallace \& White (1963) and Levine \& Marsh (1971), but the $\mathrm{pH}$ is much lower than that found by Bishop \& Mathews (1952) for the luminal contents of the ductus deferens of the rabbit. Bishop \& Mathews (1952) and White \& Wales (1961) report values of $7 \cdot 2$ and $7 \cdot 4$ for the rabbit and ram, but 
Branton (1946), Wales, Wallace \& White (1966) and Levine \& Marsh (1971) consider the $\mathrm{pH}$ of plasma from the cauda epididymidis of the bull and rat to be acidic. This may reflect species differences but a satisfactory answer to these discrepancies is still outstanding.

The presence of high levels of glycosidases and phosphatases in the epididymal plasma is in agreement with the earlier observations of Conchie \& Mann (1957) and Murdoch \& White (1968) on boars, stallions and rams. Conchie, Findlay \& Levvy (1959) also reported the levels of $\alpha$-mannosidase and $\beta-\mathcal{N}$ acetylglucosaminidase in the epididymis of the rat to be higher than in any other mammalian tissue. Histochemical studies have shown that these enzymes are present in the epididymal cells lining the duct (Risley, 1963; Martan, 1969; Moniem, 1972) and it is possible that they are actively secreted into the lumen. However, morphological evidence for active secretion is still equivocal (Nicander, 1970; Moniem, 1972) and the origin of these enzymes is by no means clear. The only substance which is generally regarded as a specific secretory product of the epididymis is GPG (Dawson, Mann \& White, 1957; Dawson \& Rowlands, 1959; Scott, Wales, Wallace \& White, 1963; Wallace, Wales \& White, 1966). In the present study, the concentration of GPC in the epididymal plasma is approximately three times that reported in ejaculated rabbit semen (Mann, 1964), but it is considerably lower than in the epididymal plasma of the ram (Scott, Wales, Wallace \& White, 1963; Jones, 1973) bull or boar (Mann, 1964; Crabo, 1965).

Thus, the milieu of spermatozoa in the cauda epididymidis is a highly specialized one and its significance in relation to sperm survival awaits further investigation.

\section{ACKNOWLEDGMENTS}

This work was supported by grants from the Ford Foundation and the Northern Ireland Ministry of Education. We are grateful to a number of members of the laboratory staff for technical assistance.

\section{REFERENGES}

Bessy, O. A., Lowry, O. H. \& Brock, M. J. (1946) A method for the determination of alkaline phosphatase with five cubic millimetres of serum. F. biol. Chem. 164, 321 .

Bishop, D. W. \& Mathews, H. P. (1952) The significance of intravas $\mathrm{pH}$ in relation to sperm motility. Science, N.Y. 115, 209.

Branton, C. (1946) Physiology and morphology of spermatozoa from different levels of the reproductive tract of the bull. M.S. thesis, Cornell University, Ithaca, N.Y. (Quoted by Salisbury, G. W. (1962) In: Spermatozoan Motility, p. 59. Ed. D. W. Bishop. Am. Assoc. Adv. Sci., Washington, D.C.)

Campbell, R. G., DotT, H. M. \& Glover, T. D. (1956) Nigrosin eosin as a stain for differentiating live and dead spermatozoa. F. agric. Sci., Camb. 48, 1.

Conchie, J., Findlay, J. \& Levvy, G. A. (1959) Mammalian glycosidases. Distribution in the body. Biochem. 7. 71, 318.

Conchie, J. \& Mann, T. (1957) Glycosidases in mammalian sperm and seminal plasma. Nature, Lond. 179, 1190.

CRABo, B. (1965) Studies on the composition of epididymal content in bulls and boars. Acta vet. scand. 6, Suppl. 5.

Crabo, B. \& Gustafsson, B. (1964) Distribution of sodium and potassium and its relation to sperm concentration in the epididymal plasma of the bull. F. Reprod. Fert. 7, 337. 
Dawson, R. M. G., Mann, T. \& White, I. G. (1957) Glycerylphosphorylcholine and phosphorylcholine in semen and their relationship to choline. Biochem. 7. 65, 627.

Dawson, R. M. G. \& Rowlands, I. W. (1959) Glycerylphosphorylcholine in the male reproductive organs of rats and guinea-pigs. Q. Fl exp. Physiol. 44, 26.

Fiske, C. H. \& Subbarow, Y. (1925) The colorimetric determination of phosphorus. F. biol. Chem. 66, 375.

Graham, E. F. \& Pace, M. M. (1967) Some biochemical changes in spermatozoa due to freezing. Cryobiology, 4, 2, 75.

Jones, R. (1973) Studies on the compositon of epididymal plasma. Ph.D. thesis, University of Liverpool.

LEVINE, N. \& MARSH, D. J. (1971) Micropuncture studies of the electrochemical aspects of fluid and electrolyte transport in individual seminiferous tubules, the epididymis and vas deferens in rats. F. Physiol., Lond. 213, 557.

Lowry, O. H., Roberts, M. R., Leiner, K. Y., Wu, M.-L. \& FARR, A. L. (1954) The quantitative histochemistry of the brain. I. Chemical methods. F. biol. Chem. 207, 1.

MANN, T. (1946) Studies on the metabolism of semen. 3. Fructose as a normal constituent of seminal plasma. Site of formation and function of fructose in semen. Biochem. 7. 40, 481.

Mann, T. (1964) The biochemistry of semen and of the male reproductive tract. Methuen, London.

ManN, T. \& LuTWAK-MANN, C. (1955) Biochemical changes underlying the phenomenon of coldshock in spermatozoa. Archo. Sci. biol. 39, 578.

Martan, J. (1969) Epididymal histochemistry and physiology. Biol. Reprod. Suppl. 1, 134.

Moniem, K. A. (1972) Some histochemical features of the mammalian epididymis. Ph.D. thesis, University of Liverpool.

MurDoch, R. N. \& White, I. G. (1968) Studies on the distribution and source of enzymes in mammalian semen. Aust. F. biol. Sci. 21, 483.

NAth, J. \& PAtt, J., JR (1970) Biochemical changes associated with freezing in ram semen. Cryobiology, 6, 522.

NICANDER, L. (1970) On the morphological evidence of secretion and absorption in the epididymis. In: Morphological Aspects of Andrology, Vol. 1, p. 121. Eds. A. F. Holstein and E. Horstmann. Gross, Verlag Gmbh., Berlin.

PACE, M. M. \& GRAham, E. F. (1970) The release of GOT from bovine spermatozoa as a test method of assessing semen quality and fertility. Biol. Reprod. 3, 140.

Quins, P. J., White, I. G. \& WIRRICK, B. R. (1965) Studies on the distribution of the major cations in semen and male accessory secretions. J. Reprod. Fert. 10, 379.

Rrsley, P. L. (1963) Physiology of the male accessory organs. In: Mechanisms Concerned with Conception, p. 73. Ed. G. G. Hartman. Pergamon Press, New York.

Salisbury, G. W. \& Gragle, R. G. (1956) Freezing point depressions and mineral levels of fluids in the ruminant male reproductive tract. Proc. 3rd Int. Congr. Anim. Reprod., Cambridge, 1956, 1, 25.

Schales, O. \& Schales, S. S. (1941) A simple and accurate method for the determination of chloride in biological fluids. 7. biol. Chem. 140, 879.

Scott, T. W., Wales, R. G., Wallace, J. C. \& White, I. G. (1963) Composition of ram epididymal and testicular fluid and the biosynthesis of glycerylphosphorylcholine by the rabbit epididymis. 7. Reprod. Fert. 6, 49.

Tuft, P. H. \& Böving, B. G. (1970) The forces involved in water uptake by the rabbit blastocyst. J. exp. Zool. 174, 165.

Wales, R. G., Wallace, J. C. \& White, I. G. (1966) Composition of bull epididymal and testicular fluid. F. Reprod. Fert. 12, 139.

Wallace, J. G., Wales, R. G. \& White, I. G. (1966) The respiration of the rabbit epididymis and its synthesis of G.P.C. Aust. F. biol. Sci. 19, 849.

Weichselbaum, T. E. (1946) An accurate and rapid method for the determination of proteins in small amounts of blood serum and plasma. Am. F. clin. Path. tech. Suppl. 10, 40.

WhIte, I. G. (1959) Studies on the estimation of glycerol, fructose and lactic acid with particular reference to semen. Aust. F. exp. Biol. med. Sci. 37, 441.

White, I. G. \& Wales, R. G. (1961) Comparison of epididymal and ejaculated semen of the ram. $\mathcal{F}$. Reprod. Fert. 2, 225. 